\section{What is already known on this topic}

Attitudes and behaviour of medical professionals are often at odds with the recommendations of the royal colleges and other bodies regarding the universal use of chaperones for intimate examinations

\section{What this study adds}

Use of chaperones by male doctors since the 1980 s and ' 90 s has substantially increased, but use by female doctors remains low

More flexible guidance is needed for general practice as well as further research into patients' views and wishes on the use of chaperones

gain more understanding of the circumstances in which problems might arise in this delicate area.
Contributors: RJ, JRo, and JRy had the original idea for the study. Data were collected by SH and SC. JB analysed the data and drafted a report. All authors wrote the paper. $\mathrm{RJ}$ is guarantor.

Funding: SH and SC were funded by the London Deanery GP Department as academic senior registrars in general practice. Competing interests: None declared.

Ethical approval: South East Multicentre Research Ethics Committee.

1 The Royal College of Obstetricians and Gynaecologists. Gynaecological examinations, guidelines for specialist practice. London: RCOG, 2002.

2 Jones RH. The use of chaperones by general practitioners. J $R$ Coll Gen Pract 1983;33:25-7.

3 Speelman A, Savage J, Verburgh M. Use of chaperones by general practitioners. BMJ 1993;307:986-7.

4 Stern V. Gynaecological examination post-Ledward: a private matter. Lancet 2001;358:1896-8.

5 Whitford DL, Karim M, Thompson G. Attitudes of patients towards the use of chaperones in primary care. Br J Gen Pract 2001;51:381-3.

(Accepted 10 February 2004)

doi 10.1136/bmj.38315.646053.F7

\title{
Use and offering of chaperones by general practitioners: postal questionnaire survey in Norfolk
}

Shaun Conway, Ian Harvey

Ten years ago in Norfolk, $65 \%$ of male general practitioners and $95 \%$ of female general practitioners never or rarely used a chaperone. ${ }^{1}$ The figures for offering chaperones were almost identical. The General Medical Council advises offering a chaperone for intimate examinations (those involving the genitals, anus, or breasts). ${ }^{2}$ The Royal College of Obstetricians and Gynaecologists advises using a chaperone for every intimate examination. ${ }^{3}$

A study of patients' preferences in Tyneside in 2001 found that $90 \%$ of women and $78 \%$ of men thought that a chaperone should be offered for intimate examinations. ${ }^{4}$ Half $(51 \%)$ of women wanted a chaperone to be used if their own male doctor was examining them. We wanted to see if the use of chaperones has changed in the past 10 years and as a result of the 2001 survey.

\section{Participants, methods, and results}

We invited a random sample of 200 (out of 348) male general practitioners in Norfolk and every female general practitioner (124) to complete a postal questionnaire. We used Epilnfo for data entry and SPSS for analysis.

Overall, $284(87 \%)$ responded. Mean age was 46.3 (men) and 43.8 (women). Only 23 were not white. The mean number of partners per practice was six. More than half $(155 ; 55 \%)$ were in dispensing practices. Three fifths of doctors $(170 ; 60 \%)$ described their practices as either rural or market town, 60 (21\%) as city, and $54(19 \%)$ as mixed or other.

The usual chaperone was the practice nurse for $75 \%$ (155/208) of those GPs who use a chaperone, but $18 \%(37 / 208)$ of doctors used a receptionist. Three fifths $(141 / 235 ; 60 \%)$ stationed the chaperone beside the patient and $36 \%(84 / 235)$ had the chaperone in the examination room but outside the curtain. Three fifths of doctors $(115 / 197 ; 58 \%)$ said that if they

This article was posted on bmj.com on 16 December 2004: http://bmj.com/cgi/doi/10.1136/bmj.38320.472986.8F

Use of chaperones by general practitioners. Values are numbers (percentages) of doctors

\begin{tabular}{|c|c|c|c|c|c|}
\hline & & Never & Rarely & Sometimes & Always \\
\hline \multicolumn{6}{|c|}{ Examining female patients } \\
\hline \multirow[t]{2}{*}{ Male doctors } & Uses a chaperone $(n=178)$ & $10(6)$ & $70(39)$ & $51(29)$ & $47(26)$ \\
\hline & Offers a chaperone $(n=176)$ & $7(4)$ & $33(19)$ & $58(33)$ & $78(44)$ \\
\hline \multirow[t]{2}{*}{ Female doctors } & Uses a chaperone $(n=106)$ & $72(68)$ & $25(24)$ & $9(9)$ & 0 \\
\hline & Offers a chaperone $(n=102)$ & $48(47)$ & $27(27)$ & $19(19)$ & $8(8)$ \\
\hline \multicolumn{6}{|c|}{ Examining male patients } \\
\hline \multirow[t]{2}{*}{ Male doctors } & Uses a chaperone $(n=178)$ & $141(79)$ & $31(17)$ & $6(3)$ & 0 \\
\hline & Offers a chaperone $(n=167)$ & $122(73)$ & $37(23)$ & $6(4)$ & $2(1)$ \\
\hline \multirow[t]{2}{*}{ Female doctors } & Uses a chaperone $(n=106)$ & $53(50)$ & $40(37)$ & $11(10)$ & $3(3)$ \\
\hline & Offers a chaperone $(n=104)$ & $39(38)$ & 32 (31) & $17(16)$ & $16(15)$ \\
\hline
\end{tabular}

The Surgery, Hingham, Norfolk NR9 4JG

Shaun Conway general practitioner Population Health Group, School of Medicine Health Policy and Practice, University of East Anglia, Norwich NR4 7TJ

Ian Harvey professor of epidemiology and public health

Correspondence to: S Conway Shaun.Conway@ nhs.net 
thought that a chaperone should be used but the patient declined then they would insist on a chaperone anyway (table).

Nearly half of male general practitioners (45\%) never or rarely use chaperones when intimately examining women. Chaperones are used rarely or never for the other three permutations of intimate examinations-only $2 \%(3 / 178)$ for male doctors examining men, $8 \%(9 / 106)$ for female doctors examining women, and 13\% (14/106) for female doctors examining men.

We asked participants to state what factors influenced their use of chaperones. Themes related to a patient's reputation were the most commonly given reasons. Supporting the patient was also important. However, the second, third, and fourth most common reasons given for use of chaperones were that the patient was a youth or minor, patient choice, and patient anxiety or need for comfort.

\section{Comment}

In the past 10 years offering of chaperones by general practitioners has increased. The proportion of male general practitioners never or rarely offering chaperones when examining female patients has fallen from $65 \%$ to $23 \%$. Norfolk is more rural than much of the United Kingdom, but these temporal changes may reasonably be extrapolated.

We found high rates for offering of chaperones. The Tyneside study indicates that patients want to be offered a chaperone, so general practitioners may be responding to societal demand. ${ }^{4}$ Merely offering a chaperone does not protect either the patient or the doctor. Stern said that even when a qualified nurse chaperone is present the patient is not protected. ${ }^{5}$ Given that in most cases $(58 \%)$ the final decision as to

\section{What is already known on this topic}

A survey 10 years ago showed that most general practitioners did not offer and use chaperones for intimate examinations

\section{What this study adds}

Offering of chaperones has increased in the past decade, but use of chaperones shows less change

whether or not to have a chaperone rests with the doctor it seems that ultimately the chaperone is there for the protection of the doctor rather than the patient.

We thank the doctors who completed the questionnaires, Jon Cooke, Sheila Ward, and Sheila Hawkins.

Contributiors: SC had the original idea for this study, which was to follow up Speelman's work 10 years on, ran the project, and wrote the bulk of the report. IH commented on the design, analysis, and write up and is guarantor.

Funding: Eastern Region NHS R\&D department via an enterprise award to SC.

Competing interests: None declared.

Ethical approval: Norwich Local Research Ethics Committee.

1 Speelman A, Savage J, Verburgh M. Use of chaperones by general practitioners. BMJ 1993;307:986.

2 General Medical Council. Intimate examinations. In: Duties of a doctor 2002. London: GMC, 2002. www.gmc-uk.org/standards/intimate.htm (accessed 2 Dec 2004)

3 Royal College of Obstetricians and Gynaecologists. Gynaecological examinations: guidelines for specialist practice. London: RCOG, 2002. www.rog.org.uk resources/public/WP_GynaeExams4.pdf (accessed 2 Dec 2004).

Whitford DL, Karim M, Thompson G. Attitudes of patients towards the use of chaperones in primary care. Br J Gen Pract 2001;51:381-3.

5 Stern V. Gynaecological examinations post-Ledward: a private matter. Lancet 2001;358:1896-8.

(Accepted 24 November 2004)

doi $10.1136 /$ bmj.38320.472986.8F

\section{Good enough general practice}

I had admitted an elderly woman with severe sciatica to the community hospital. She needed care while her pain continued. During her second evening in hospital, nurses became concerned about her deteriorating mobility, and I found that she had developed a flaccid paraparesis suggestive of cauda equina compression. I needed urgent specialist advice and telephoned the neurosurgical registrar in the city 30 miles away.

Suddenly I was struggling to survive detailed neurological interrogation. Were hip flexion and extension equally weak? Just what did I mean when I said ankle dorsiflexion was "rather" weak? Was there a sensory level on the trunk? How weak was plantar flexion? What was her post-voiding residual urine volume? At what root level did I consider the deficit was?

This was a clash of medical cultures; he from the sharp peak of the super specialty and I from the broad plains of general practice. We were speaking different languages, and mine was clearly failing to impress him. Eventually, a sufficient number of stuttered responses allowed him to advise on immediate management. As I put down the telephone, I felt deflated and experienced a pang of inadequacy.

During my career, I've forgotten more than I know. Inevitably we lose skills that we seldom practise and retain those that we constantly need. Yes, my neurological examination technique had lacked precision, and I made a note to sharpen it up. But had it been "good enough" to allow recognition of the emergency with appropriate referral? I think so. As Richard Smith highlighted in his address to new medical students, ${ }^{1}$ contentment with being "good enough" is a prerequisite for a happy medical career-and that advice surely applies to the wide expanses of general practice as much as to any other medical discipline.

The specialist registrar called back to discuss transfer arrangements. "Sorry about the poor performance in the viva," I said.

"I'm sure I'd easily fail a viva in general practice," he laughed. "Yes," I said, "I'm pretty sure you would."

Malcolm Lindsay general practitioner, the Health Centre, Galashiels (Malcolm@lindsaymk.fsnet.co.uk)

1 Smith R. Thoughts for new medical students at a new medical school. BMJ 2003:327:1430-3.

We welcome articles up to 600 words on topics such as A memorable patient, A paper that changed my practice, My most unfortunate mistake, or any other piece conveying instruction, pathos, or humour. Please submit the article on http:// submit.bmj.com Permission is needed from the patient or a relative if an identifiable patient is referred to. We also welcome contributions for "Endpieces," consisting of quotations of up to 80 words (but most are considerably shorter) from any source, ancient or modern, which have appealed to the reader. 